\title{
Health Concerns and Management of Select Veterinary Drug Residues
}

Ronald E. Baynes ${ }^{1 *}$, Keith Dedonder ${ }^{2}$, Lindsey Kissell ${ }^{1}$, Danielle Mzyk ${ }^{1}$, Tara Marmulak ${ }^{3}$, Geof Smith $^{1}$, Lisa Tell ${ }^{3}$, Ronette Gehring ${ }^{2}$, Jennifer Davis ${ }^{1}$, and Jim E. Riviere ${ }^{3}$.

${ }^{1}$ North Carolina State University, Raleigh NC 27607, USA

${ }^{2}$ Kansas State University, Manhattan, KS, USA

${ }^{3}$ University of California, Davis, CA 95616, USA

*Corresponding Author

Dr. Ronald E. Baynes

College of Veterinary Medicine

North Carolina State University

1060 William Moore Dr.

Raleigh, NC

USA

(919) 513-6261 (T)

(919) 513-6358 (F)

Ronald_Baynes@ncsu.edu 


\begin{abstract}
The aim of this manuscript is to review the potential adverse health effects in humans if exposed to residues of selected veterinary drugs used in food-producing animals. Our other objectives are to briefly inform the reader of why many of these drugs are or were approved for use in livestock production and how drug residues can be mitigated for these drugs. The selected drugs include several antimicrobials, beta agonists, and phenylbutazone. The antimicrobials continue to be of regulatory concern not only because of their acute adverse effects but also because their use as growth promoters have been linked to antimicrobial resistance. Furthermore, nitroimidazoles and arsenicals are no longer approved for use in food animals in most jurisdictions. In recent years, the risk assessment and risk management of beta agonists, have been the focus of national and international agencies and this manuscript attempts to review the pharmacology of these drugs and regulatory challenges. Several of the drugs selected for this review can cause noncancer effects (e.g., penicillins) and others are potential carcinogens (e.g., nitroimidazoles). This review also focuses on how regulatory and independent organizations manage the risk of these veterinary drugs based on data from human health risk assessments.
\end{abstract}

\title{
Introduction
}

Regulatory organizations such as the United States Food and Drug Administration (US FDA) and the European Medicinal Agency (EMA) and independent organizations such as the Joint World Health Organization/Food and Agricultural Organization Expert Committee on Feed Additives (JECFA) have determined tolerances and maximum residue limits (MRLs), respectively, for the various food commodities such as muscle, liver, kidney, fat, milk, and eggs. The MRLs derived by JECFA are recommended to the Codex Alimentarius Commission (CAC), which as the risk manager, determines whether or not to establish international standards for residues of veterinary drugs in terms of MRLs. The term tolerance is used by the US FDA while other countries and organizations use MRLs. Other developed countries that are not part of the EU develop their own MRLs. Most developing countries adopt EU or Codex MRLs. For these reasons, this review will focus on approaches adopted U.S., EU, and Codex. Readers are advised to consult the guidance documents from these national and international agencies for details on how these safe levels are derived. The safety evaluation of these compounds are described in public documentation provided by the U.S. and EU and through the JECFA reports and monographs. The U.S. FDA, EMA, and JECFA conduct similar risk assessments in their safety evaluation of veterinary drug residues as described in more detail in the next paragraph. The EU has since 2009 adopted MRLs established by CAC without requiring an additional MRL application and evaluation by EMA provided that the EU delegation at the CAC did not object to the MRLs. For the most part, the risk assessment methods are indeed very conservative by making allowance for the most sensitive member of the human population. However, when residue levels in the above food animal commodities exceed the tolerance or MRL, the consumer could develop adverse health effects. Potential adverse health effects can include allergic reactions to several antimicrobial drug classes, blood dyscrasias, carcinogenicity, and cardiovascular toxicity, to mention a few, but reflect several of the potential adverse health effects associated with exposure to the drugs selected for this review.

Residues at or below tolerance or MRL is considered safe when food at that level is consumed daily for a life-time. Derivation of the tolerance or MRL requires algorithms and 
several toxicological, pharmacological, and microbiological data packages which will be briefly described. This is a risk assessment process where a standard battery of safety studies in animal and/or humans as well as in vitro studies are used to determine the acceptable daily intake (ADI). The resulting toxicological ADI is often determined from the lowest no-observable-adverseeffect level (NOAEL) and/or lowest observable adverse effect level (LOAEL) gleaned from the animal and/or human studies. These NOAELs and LOAELs are often adjusted by uncertainty factors to account for species differences (1-10 for animal to human extrapolations) and intraspecies differences (1-10 for variability within a population). The ADI is then adjusted with food consumption values for various tissues (300 grams for muscle, 100 grams for liver, 50 grams form kidney, 50 grams for fat, and if a dairy approval, 1500 grams for milk) to obtain MRLs or tolerance for each tissue. This requires kinetic data for each tissue and this is used to ensure that the total food basket of residues at each tissue MRL or tolerance results in less than the daily intake. Different jurisdictions may use slight modifications such as allocations of ADIs in how MRLs and tolerances are calculated (Baynes et al., 1999), and a comparison is briefly discussed at the end of this review.

This paper focuses on several veterinary drugs that are (1) more likely to cause adverse health effects in humans consuming these drug residues in livestock products and/or (2) not approved or no longer approved for use in food producing animals because of their presence in food put human health at risk. We have focused on the antimicrobial drug class because they are among the most widely used drugs in the livestock industry. The drugs from this antimicrobial class that is the focus here include the penicillins, tetracyclines, aminoglycosides, sulfonamides, chloramphenicol, arsenicals, and nitroimidazoles. While there are several nonsteroidal antiinflammatory drugs approved or used off label in food animals, this paper focuses on a nonsteroidal anti-inflammatory drug, phenylbutazone, because it is of high regulatory concern although not approved for use in food animals. The third drug class we focused on is the betaagonist which are known to have caused acute adverse health effects and deaths in humans following exposure to related residues in animal meat.

There are several other drug classes that are used in food-producing animals that could result in residues but will not be presented in this review for several reasons. For example, the antiparasiticides are more widely used than many of the antimicrobials but they are very selective and their drug residues are least likely to affect human health compared to those drug classes selected for this review. The hormonal growth implants and their use in food-producing animals are a high regulatory concern and because of the disagreements between the regulators in the safety assessments (e.g., between the EU and US), this will require a more detailed and separate review that documents the scientific merits and issues pertaining to their use, adverse effects, and risk assessment of these drugs. The EU has forbidden the use of hormonal substances as growth promoters in food producing animals and since the establishment of the EMA in 1995, there have been no request for authorization of such products (Grein and Duarte, 2014). In essence, the scope of this review is limited to those drugs and drug classes that were formerly approved or more widely used at the global level and for which there is growing scientific consensus about their judicious use in animal agriculture, potential adverse effects, and risk management steps. However, the reader should be aware that many of the adverse reactions reported in this manuscript are not from direct evidence of food related events or reported cases of consumption of food containing these drug residues. The literature is limited in relating drug exposure via food and adverse events; therefore, most of the adverse effects in the literature are 
from human exposure to the drug as a human medication and/or related animal and human testing.

For each drug class, we will review (1) current as well as former drug use in veterinary medicine in the U.S., (2) adverse health effects (cancer and noncancer effects) in humans and specifically mention from the limited available literature where adverse events have been reported, and (3) risk management of these specific drug residues as described by the U.S., EU, and Codex. Our discussion on risk management of these selected drugs will be focused on regulatory status in predominantly the U.S. and EU with respect to its limited use in defined jurisdictions and special mention of withdrawal times where uniquely appropriate. Risk management measures can also include testing of meat and milk using screening and confirmatory tests and description of these tests for the various products is beyond the scope of this review. The reader should be aware that there are consequences in the advent of residue violations; that is, residue levels that exceed the tolerance or MRL. Several of the drug classes discussed in this review are not approved or no longer approved for use in food animals in many jurisdictions although drug residue violations in livestock products have been reported.

\section{Antimcirobials}

\section{Use in veterinary medicine:}

These antimicrobial drug classes are currently used and licensed in many jurisdictions for therapeutic indications in food animal veterinary medicine. However, some regulatory agencies no longer approve their use as growth promoters in food-producing animals. This highlights the distinction between therapeutic use which alleviates pain and suffering and growth promotion which aims to increase the rate of weight gain and improved feed efficiency thus achieving market weight in less time than if the antimicrobials were not in the feed. Because of antimicrobial resistance concerns, many countries, including those in the European Union (EU) have withdrawn approvals for their use for growth promotion since January 2006. In recent years, the US FDA has also discouraged the use of these antimicrobials as growth promoters in livestock and have published plans to phase out the use of these antimicrobials as growth promoters as stated in the GFI \#213 document (US FDA, 2013). Because of antimicrobial resistance concerns, it is very likely in the future that only therapeutic use will be allowed in all jurisdictions and the veterinarian will be more involve in directly managing microbial infection on livestock farms to ensure the prudent use of antimicrobials. Effective Jan $1^{\text {st }} 2017$ in the U.S., the veterinary feed directive (VFD) will be expanded to antibiotics used in feed for prevention control and treatment of disease and over-the-counter (OTC) sales of these drugs including those described below will not be allowed.

Penicillins. In the U.S., there are about 27 approved penicillin products and only 6 of these require a veterinary prescription. There are currently 10 approvals available as over-thecounter (OTC) feed additives or OTC water additives. Many of these feed or water additives have therapeutic indications such as use for the treatment of erysipelas in turkeys (e.g., penicillin g potassium) or they may have indications for increased rate of weight gain and improved feed efficiency in poultry or swine (e.g., penicillin g).

Tetracyclines. There are approximately 122 tetracycline approvals in the U.S. which include various salts of tetracycline, oxytetracycline, and chlortetracycline with approximately 30 of these products approved for therapeutic use. The majority of these drugs are OTC products that may be combined with other antimicrobials such as sulfonamides and approved for use in 
almost all food animal species including fish and honey bees. In addition to bacterial infections, these drugs have been approved in some cases to treat Mycoplasma in poultry. Many of these drugs are used to control and/or treat bacterial enteritis or pneumonia and may be administered for as few as 3-5 days or as long as several weeks in feed or water.

Aminoglycosides. Gentamicin and neomycin make up the majority of aminoglycosides used in livestock production. In the U.S., there are about 15 gentamicin sulfate approvals and they are all OTC products. There is one product for treatment of infectious keratoconjunctivits caused by Moraxella bovis in cattle. Seven of the 15 products are OTC water additives for use in swine and poultry for several days often to treat or control bacterial enteritis in piglets or young chickens and turkeys. There are also 15 neomycin approvals often used to control and treat for bacterial enteritis with about 14 approvals used as feed and water additives. One other aminoglycoside used in food animals, streptomycin has 6 approvals which are mostly used therapeutically in cattle and swine.

Sulfonamides. The sulfonamides are one of the oldest groups of antimicrobials and have been used in food animal production for over 60 years. Sulfonamides are still utilized in cattle, swine and poultry, however their use has somewhat declined in some jurisdictions in spite of this drug class being the third most commonly used antimicrobial used in food animals. A recent study across 25 European countries found that sulfonamides were the third most popular class of antimicrobials used in veterinary medicine (behind tetracyclines and penicillins) and that sulfonamides represented $11 \%$ of the total sales of veterinary antimicrobial drugs across Europe in 2011 (Grave et al., 2014). Resistance to sulfonamides has been reported for several of these drugs (Lanz et al., 2003; Gibbons et al., 2014). Oral sulfamethazine and sulfachlorpyridazine are commonly given to calves (including veal calves) with diarrhea, although there is limited efficacy data that would support this use. In the swine industry, sulfamethazine is used in pigs as a treatment for septicemia and bacterial pneumonia (Riviere and Papich, 2009). Sulfamethazine is also used in turkeys for the treatment of Escherichia coli and Pasteurella multocida (fowl cholera). Occasionally potentiated sulfonamides are used in very young chickens as well (for example a sulfadimethoxine/ormetroprim combination is approved in many countries). Sulfonamides are also utilized occasionally in the poultry industry to control coccidiosis. Use in broilers is rare as the growing cycle is generally too short to allow sufficient withdrawal intervals.

Chloramphenicol. Chloramphenicol is an older antibiotic that received approval from the U.S. Food and Drug Administration for human use in 1950. It is not approved for use in any food producing animal and is prohibited from extra-label use in these species (US FDA 21CFR530.41). It is used in companion animal species and this antibiotic has broad-spectrum antimicrobial activity covering Gram-positive and negative organisms, anaerobes and rickettsiae. It is widely distributed into most tissues and fluids including penetrating the central nervous system, placental and mammary gland barrier (Riviere and Papich, 2009).

Arsenicals. Roxarsone as 3-Nitro ${ }^{\circledR}$ was approved in 1944 as the first arsenical for use in food animals. Other arsenic-based feed and water additives were approved for use in foodproducing animals to improve rate of weight gain, feed efficiency, and pigmentation, as well as control and treat bacterial and coccidial infections in chickens, turkeys and swine. These products contained nitarsone, arsanilic acid, or carbarsone. These organic arsenicals are no longer approved for use in food-producing animals in most jurisdictions.

Nitroimidazoles. Nitroimidazoles are a class of drugs that have both antibacterial and antiprotozoal activity. These drugs are no longer approved for use in food animals. Previously, 
some nitroimidazoles were labeled for the treatment of histomoniasis in turkeys, swine dysentery and recommended as a treatment for trichomoniasis in bulls. Members of this drug class include: metronidazole, dimetridazole, ipronidazole, ronidazole and tinidazole. Metronidazole is the most commonly studied compound of this group.

\section{Adverse health effects in humans}

Drug residues above the regulatory safe concentration in food items established by U.S. FDA (tolerances), EMA (MRLs), or JECFA (MRLs) for the above antimicrobials could result in either allergic reactions, disruption of normal intestinal human flora in the intestine, blood dyscrasias, cancer, and/or development of antimicrobial resistance making it difficult to treat human infections. The aminoglycosides can also cause ototoxicity and nephrotoxicity, however this typically occurs only with high or frequent dosing and is unlikely to be a result of oral exposure from food residues. Of these potential adverse reactions, effects on human intestinal flora and allergic reactions are most likely following oral exposure. The reader should also recognize allergic reactions in the naïve human population (sensitization) versus the allergic response in a sensitized human population where there was drug exposure to stimulate memory response.

Penicillins. Approximately $4-11 \%$ of the human population are believed to be allergic to penicillin and related drugs (Dayan, 1993), therefore exposure to this drug class via food animal residues puts them at risk for developing allergic reactions that may range from minor reactions, such as a skin rash, to severe anaphylaxis. Although the true incidence/prevalence and mortality associated with drug-induced anaphylaxis is unknown in western countries, several epidemiological studies investigating penicillin and anesthetic agents given during the perioperative period showed these drugs were associated with IgE-mediated allergic anaphylaxis (Thong and Tan, 2011). The immunogenicity of the penicillins is not based on the drug itself but based on the penicilloylation of proteins after the beta-lactam ring is open. Therefore human reactions are based on penicilloylated residues in meat and milk. It is believed that 10 IU (0.6 $\mu \mathrm{g}$ ) or $6 \mathrm{ng} / \mathrm{ml}$ of drug in milk can cause this reaction (EMA, 2008). This is one of the reasons why the MRL and tolerance for this drug in milk is less than this concentration in many jurisdictions such EU and JECFA (MRL $=4 \mathrm{ng} / \mathrm{ml}$ ). These levels are also applicable to amoxicillin and ampicillin, and is applicable to the penicillin parent compound although the penicillin metabolites can also cause a hypersensitive reaction in humans. In the U.S., there is a zero tolerance established for residues of penicillin and its salts in milk or any processed food in which such milk is used. However, there is a "safe level" of $5 \mathrm{ng} / \mathrm{ml}$. "Safe levels" in the U.S. are not and cannot be transformed into tolerances that are established for animal drugs in milk, and a "safe level" does not supercede the tolerance of zero. While there is no evidence that exposure to legal penicillin residues in food can cause sensitization to penicillin, there is sufficient evidence that consumption of beef or pork products containing violative penicillin residues caused anaphylactic reactions (Dayan, 1993; Kanny et al., 1994; Raison-Peyron et al., 2001; Gomes and Demoly, 2005). In many of these cases, the investigators were able to confirm presence of the drug in the meat consumed, that the hypersensitivity reactions were because of benzyl penicillin and not sensitivity to the consumed meat products. Further evidence of an adverse drug reaction was found by testing patient sensitivity to penicillin (Kanny et al., 1994). Some authors have proposed the inefficiency of oral exposure for immunization (Dayan, 1993), however, there are insufficient rigorous studies to support the claim that parenteral administration tends to be more sensitizing than the oral route. 
Tetracyclines and Aminoglycosides. The immunogenicity of these two antimicrobials have not been as well studied as the beta-lactams, but the amino sugars appear to be important epitopes for aminoglycosides. Anaphylaxis to tetracyclines is rare compared to the beta-lactam drugs described above, however, human exposure to minocycline (a tetracycline used to treat acne) has been associated with approximately 13\% adverse cases of which very few were anaphylactic reactions (Goulden et al., 1996; Jang et al., 2010). Furthermore, there is no reported evidence to date of human consumption of meat or milk products containing tetracyclines or aminoglycosides having resulted in adverse reactions related to what we have associated with aminoglycoside or tetracycline toxicity (Doyle, 2006). The EMA MRLs for tetracyclines and gentamicin are based on microbiological ADIs. These were assessments of the impact of these drugs on human intestinal microbial flora from human volunteers for tetracyclines (no induction of resistant enterobacteriacea) and only from in vitro data for gentamicin (MIC 50 for the most sensitive strain) as human data was not available.

Sulfonamides. The authors are not aware of any reports in the published literature reporting toxicity or other adverse reactions in humans associated with consumption of animal products containing trace amounts of sulfonamides. However, adverse drug reactions in humans to sulfonamide drug exposure are common. Approximately half of the reported cases in humans are skin reactions which can range from a mild rash to a severe toxidermia and/or epidermal toxic necrolysis (Choquet-Kastylevsky, 2002). However blood dyscrasias including hemolytic anemia, neutropenia, thrombocytopenia and pancytopenia have also been described and represent about $15 \%$ of cases associated with sulfonamide use in humans. Acute liver injuries (hepatitis) are also frequently reported in humans, however these have primarily been associated with cotrimoxazole (Choquet-Kastylevskey et al., 2002). Although the mechanisms of these cases in humans have not been fully elucidated, an immune-mediated reaction involving reactive metabolites has been suspected in most cases. Since the risk of severe hypersensitivity reactions is considered high, many of the long-acting sulfonamides are no longer available on the human market. In addition, topical sulfonamide creams are considered potent contact sensitizers and their use is generally discouraged. Another concern associated with the ingestion of sulfonamides is thyroid cancer. A chronic feeding study in mice done by the National Center for Toxicological Research (NCTR) found that sulfamethazine produced a dose-dependent increase in follicular cell adenomas of the thyroid gland in both male and female mice. This increase was noted after feeding moderate to high levels of sulfamethazine for 18 to 24 months (Littlefield et al., 1989).

Chlorampheicol. Bone marrow suppression resulting in aplastic anemia is the most significant and widely recognized adverse effect associated with chloramphenicol use in humans (Eliakim-Raz et al., 2015). However, no dose relationship or threshold dose for the induction of aplastic anemia has been identified (Wongtavatchai et al, 2004). Since only a small exposure to chloramphenicol may lead to aplastic anemia, of particular importance in veterinary medicine, persons handling and administering the drug may also be at risk. A feed lot rancher died in 1981 from aplastic anemia acquired from exposure through an open wound on his hand when treating a herd of cattle for pneumonia (Settepani, 1984).

The Joint FAO/WHO Expert Committee on Food Additives (JECFA) classifies chloramphenicol as genotoxic and a possible carcinogen. The limited studies available on the carcinogenicity of chloramphenicol prevent a definitive classification of the drug.

Multiple animal-derived food products including milk, honey, meat from poultry, cattle and pork, fish and other seafoods have been identified as being contaminated with 
chloramphenicol presumably after use of chloramphenicol at therapeutic doses (CONTAM, 2014). However, there are no data to implicate the presence of residues of chloramphenicol in food consumed by humans as a cause of aplastic anemia.

Arsenicals. While there are some organic forms of arsenic that have been found to be carcinogenic, it is the inorganic arsenic that is of greater concern in this respect. The latter is classified by the IARC as a human carcinogen; meaning it is a known carcinogen in humans. Chronic exposure to inorganic arsenic in humans has been linked to noncancer effects such as skin lesions, neurotoxicity, cardiovascular diseases, abnormal glucose metabolism and diabetes (EFSA, 2009). There is also a need for further evidence supporting the dose-response relationships for many of these adverse effects. EFSA also reported that the provisional tolerable weekly intake (PTWI) of $15 \mu \mathrm{g} / \mathrm{kg}$ b.w. established by the JECFA was no longer appropriate as adverse effects had been reported at exposures lower than those reviewed by the JECFA. The BMDL01 values for the relevant health endpoints, i.e. skin lesions, cancers of the skin, urinary bladder and lung, ranged from 0.3 to $8 \mu \mathrm{g} / \mathrm{kg}$ b.w. per day. In 2015, ESFA reported that for average and high level consumers in the EU, exposure to inorganic arsenic in their diet is estimated to be within the range of the BMDL01 values, and there is little or no margin of exposure, and the "risk to some consumers cannot be excluded" (EU, 2015). This report also list the MRLs for inorganic arsenic in several rice products as ranging from 0.1 to $0.3 \mathrm{ug} / \mathrm{kg}$, but no MRLs were reported for livestock products.

Until recently, it was thought that all organic arsenic consumed was excreted without transformation. Newer information has disproved this and inorganic arsenic has been detected in animals administered an organic arsenical, roxarsone (Conklin et al, 2012). Prior to this publication, the U.S. FDA performed a study in 2009 which detected higher inorganic arsenic in the livers of broiler chickens treated with the drug 3-Nitro ${ }^{\circledR}$ (roxarsone) than in untreated chickens, even after the 5 day withdrawal time associated with roxarsone (US FDA, 2009). The levels of inorganic arsenic in these livers were very low $(1.04 \mu \mathrm{g} / \mathrm{kg}$ wet weight of liver). While the actual concentration of inorganic arsenic in muscle tissue of these animals could not be determined due to technical limitations of the assay, total arsenic levels in muscle were much lower than in the liver, suggesting the amount of inorganic arsenic consumed in muscle tissue could be toxicologically insignificant. Inorganic arsenic is rapidly excreted from the body in humans, thereby decreasing adverse health potential even further. Furthermore, if humans consumed $0.1 \mathrm{~kg}$ of liver per day then exposure to $1.04 \mu \mathrm{g}$ arsenic/kg liver will expose humans to $0.1 \mu \mathrm{g}$ arsenic per day or $0.1 \mu \mathrm{g} / 70 \mathrm{~kg}$ per day or $0.0014 \mathrm{mg} / \mathrm{kg}$ b.w/day; this will be less than BMDL01 of 0.3 to $9.0 \mu \mathrm{g} / \mathrm{kg}$ b.w. per day.

Nitroimidazoles. Although these drugs are no longer approved for use in food animals in the United States, Canada and the European Union they are still directly used in people without reports of cancer associated morbidity (Bendesky et al., 2002). According to the International Agency for Research on Cancer (IARC), there is sufficient evidence to consider metronidazole as an animal carcinogen, but insufficient to do so for humans (Bendensky et al., 2002). Metronidazole is also used extensively in companion animal veterinary medicine for a variety of indications (Riviere and Papich, 2013).

\section{Risk management.}

As described above, there are many antimicrobial approvals which can be broadly classified as therapeutics drugs, drugs used for control and prevention of disease, and until recently in the U.S., drugs that can be used as growth promoters which are often administered via 
water or feed additives. Many of the latter have very short withdrawal times and some may have as short as zero days withdrawal when used according to label. Irrespective of drug claims, residue violations are more likely to occur when (1) these drugs are used in an extralabel manner but use the withdrawal time on the label and/or (2) use in a label manner and do not follow the approved withdrawal time. The dairy industry in all countries are very concerned about antimicrobial residues for the many reasons described above, therefore they employ very sensitive screening tests to ensure that the bulk tank contains whole milk at drug concentrations below the established tolerances or MRLs for that drug in milk. Residue violations in milk for these antimicrobials have declined over last 3 decades and residue violations in meat and meat products have been declining in most western countries. The US FDA national Milk Drug Residue Sampling Survey of about 2000 dairy farms with half of these farms being the targeted group based on history of drug residues and the other half were the randomly selected group (US FDA, 2015). Of the originally 1918 milk samples that were tested for 31 different drug residues, only $1 \%$ of the samples from the targeted group had residue violations and $0.4 \%$ of the random group had residue violations. The antimicrobial florphenicol, was the most frequently confirmed along with 11 other drugs which were also antimicrobials. Unfortunately, none of these 12 drugs (except for gentamicin) are approved for use in lactating dairy cows. Of the antimicrobials relevant to this review, one sample contained the aminoglycoside, gentamicin.

Finally, there is very little is known about the partitioning of these antimicrobial drugs into the various milk fractions (e. g., whey proteins, butter fat) following processing and whether cooking can influence the stability of these antimicrobials. Older studies have reported that chlortetracycline can be converted to isochlortetracyline which lacks sensitizing properties (Shirk et al., 1956) and that oxytetracyline is converted to $\alpha$ - and $\beta$-apooxytetracylines (Katz et al., 1973) which may reduce the risk to adverse health effects to tetraccylines.

Historically, tissue residues from sulfonamide use in food animal species have been a major regulatory concern (Bevill, 1989). In fact, for many years this class of antimicrobial was responsible for more violative residues than any other drug. For example in 1977, 13.1\% of pigs had violative sulfonamide residues detected at slaughter (Bevill, 1984). The primary reasons for the occurrence of sulfonamide residues are failure to observe the proper withdrawal time, improper feed mixing, and improper cleaning of feeding and/or feed mixing equipment that allowed cross-contamination of feed. The electrostatic nature of sulfamethazine when used in a powdered form caused particles to adhere to contact surfaces. Therefore carryover of drug into later batches of unmedicated feed was common and resulted in residues (Cordle, 1989). Excretion of sulfamethazine in the feces and urine could also cause recontamination of the environment in swine and poultry houses and result in residues in the next group of animals when cleaning was not properly done between groups.

Regardless of no reported cases of sulfonamide related adverse effects from food containing sulfonamides, sulfonamides remain a drug of great regulatory concern worldwide. In the United States, the extralabel use of sulfonamides have been prohibited from use in adult dairy cows, which are defined as any female greater than 20 months of age regardless of milking status (Davis et al., 2009). This prohibition was instituted due to the concern over carcinogenicity noted in rodents, coinciding with reports of sulfonamide residues detected in up to $73 \%$ of commercial milk samples. In the swine and poultry industries, granulated forms of sulfamethazine have been developed that are less electrostatic and thus are less likely to cling to feed mixing equipment. However extreme caution is still utilized when making feeds with sulfonamides or following administration in the water. Extended withdrawal times, beyond that on the product label are 
also commonly used in the industry to avoid any residue issues; this is especially the case for meat and dairy products targeted for export. Pharmacometric studies in our laboratory (Buur et al., 2006; Mason et al., 2015) suggest that the U.S. labeled withdrawal time of 15 days for sulfamethazine (Table 1) should be extended at least 5 to 6 days to account for population variability in a swine herd.

JEFCA (Wongtavatchai, 2004) was unable to determine an ADI for chloramphenicol because there was insufficient information available to establish a threshold dose for the development of aplastic anemia, assess its carcinogenicity, or reproductive toxicity. They also noted that they were unable to identify a suitable marker residue in cattle and pigs, for which the radio-depletion studies were considered inadequate. Codex (CAC, 2014) indicated in their risk management recommendations that as there is no safe level of residues of chloramphenicol or its metabolites in food that represents an acceptable risk to consumers, competent authorities should prevent residues of chloramphenicol in food by not using chloramphenicol in food producing animals".

In the US, there are no approved chloramphenicol drugs for use in livestock and the extra-label use of chloramphenicol in any food-producing animal is prohibited. There is no approved tolerance for chloramphenicol in food products and any residue detected is considered violative.

Similarly, in the EU, chloramphenicol is listed in Annex IV of Council Regulation No. 2377/90 (EEC, 1990) and revised more recently listed in Table 2 of EU documents 470/2009 and 37/2010 (EU, 2010) as a list of prohibited substances; although this list appears to be a limited list of 10 substances. Until 2005, the zero tolerance policy lead to the rejection of a number of crustacean and honey imports into the U.S. and the EU in the early to mid-2000s impacting international trade (Love et al., 2011; Tran et al., 2012; Wongtavatchai et al., 2004). Subsequently, the European Commission published a decision in January 2005 (Commission Decision, 2005) to no longer regulate chloramphenicol at a zero tolerance level. The European Commission set a minimum required performance limits (MRPLs) or /reference point for action (RPA) for chloramphenicol at $0.3 \mu \mathrm{g} / \mathrm{kg}$. Foods of animal origin containing residues at or above the RPA are considered to be noncompliant with EU legislation and should not be marketed. The source of contamination is then investigated. For foods containing chloramphenicol below the RPA, the cause of the contamination is investigated, but the product may still be marketed. The European Food Safety Authority (EFSA) Panel on Contaminants in the Food Chain (CONTAM, 2014) determined that exposure to animal-derived food products contaminated with chloramphenicol at or below $0.3 \mu \mathrm{g} / \mathrm{kg}$ are unlikely to be a health concern for aplastic anemia or reproductive or hepatotoxic effects. It should be noted that EU 470/2009 states that setting RPAs should in no way serve as a pretex for supporting the illegal use of prohibited drugs such as chloramphenicol.

Despite the low levels of arsenicals and the low risk for adverse human health events, the drug manufacturers suspended production of these drugs for use in food animals. This is due to the Delaney Clause for new animal drugs of the U.S. Federal Food, Drug, and Cosmetic Act, which states that the FDA cannot approve drug use in food-producing animals if the drug or its metabolites can cause cancer. There is an exception to this clause, known as the DES proviso which allows cancer-causing compounds (or compounds with cancer-causing metabolites) to be used in food-producing animals if 1) the drug does not harm the animal and 2) tests approved by FDA do not detect residues of the drug in any food from the animal (CFR 500). In 2015, the drug company voluntarily withdrew all new animal drug approvals and supplements for roxarsone, as 
well as arsanilic acid and carbarsone. That left only nitarsone containing products on the market in the US. The approvals and marketing for this drug will be phased out and withdrawn in Fall 2015. There is no evidence that the EU has ever approved the use of arsenicals in animal feed based on list in their Annex (EMA, 2009), which may be related to lack of science supporting health or safety standards for such use. This substance is not listed in Prohibited Substance list of Table 2 of the EU document 37/2010, however, it is left to be assumed that these substances are were and are not approved for use in food animals. Similarly, JECFA, has not recommended MRLs for these arsenical substances for use in food animals; this organization has provided recommendations for contaminants in its safety assessment (CAC, 2011).

JECFA recently reviewed the use of nitroimidazoles in food-producing animals and concluded that no acceptable daily intake could be established for metronidazole, dimetridazole and ipronidazole. JECFA was unable to evaluate the toxicological and residue depletion studies in food-producing animals for nitroimidazoles because relevant data were not made available to the committee. Therefore, no acceptable daily intake (ADI) or maximum residue level (MRL) were recommended by JECFA for metronidazole, dimetridazole and ipronidazole due to specific human health concerns. Therefore no acceptable level of risk to the consumer could be identified and use of nitroimidazoles in food-produced species could pose a significant health concerns to the consumer. The risk management recommendations from Codex are that "competent authorities should prevent residues of metronidazole in food, which can be accomplished by not using metronidazole in food producing animals" (CAC, 2013). In the EU, these drugs are listed as Prohibited Substances in Table 2 in the Annex of Regulation (EU) 37/2010 and indicates that MRLs cannot be established. Similarly, in the US, no tolerance has been established for any nitroimidazole compound because there are no approved products for use in food producing animal species and any extralabel use is strictly prohibited. In summary, all nitroimidazoles are not approved for use in food producing animals in the U.S., EU, and many other OECD countries due to the risk for carcinogenesis. No ADI, tolerance limit or MRL has been established for any nitroimidazole drugs and as a result any detectable concentration would be consider a violation.

Table 1 provides a list of drugs along with their respective U.S. tolerance, EU MRL, and meat and milk withdrawal time for selected drugs. Sulfamethazine represents an example where there is harmonized MRLs and tolerances. However, there are notable differences between tolerances and MRLs for reasons related to how the risk assessment was conducted. Because of these differences, there may be differences in approved milk and/or tissue withdrawal times across jurisdictions. The reader should be reminded that there are many different formulations of any given antimicrobial drug and therefore the withdrawal times listed in Table 1 for say penicillin cannot be applied to all formulations of penicillin although the MRLs or tolerances apply to penicillin. These regulatory standards are used in the management of antimicrobial residues at the farm level before milk, slaughter, and further food processing.

\section{Phenylbutazone}

\section{Use in Veterinary Medicine.}

Phenylbutazone (PBZ) was introduced into human medicine in 1949 as a non-steroidal anti-inflammatory drug (NSAID) for use in the treatment of acute and chronic inflammatory pain. In veterinary medicine, PBZ is currently approved for use in horses and dogs to treat pain and reduce inflammation, particularly when associated with musculoskeletal conditions 
including chronic laminitis and degenerative joint disease. It is not approved for use in any foodproducing animal, and its labeled use in horses is limited to those not intended for food. Although PBZ is not approved, the pharmacokinetics of this drug has been described in several veterinary species, including cattle, llamas, sheep, goats, pigs, donkeys and rats (Lees et al. 2004, Lees and Toutain, 2013). Ruminant species demonstrate a prolonged elimination half-life (207 hours in neonatal calves and 42-65 hrs in cows), allowing for prolonged dosing intervals (Arifah et al, 2002; Cheng et al 1997; Cheng et al 1998; de Veau et al 2002) Every other day or every third day dosing makes this an attractive drug to use for chronic pain issues in these species, but also leads to the need for prolonged withdrawal times (Smith et al 2008). The plasma half-life is short in the horse $(4.0-6.0 \mathrm{hrs})$, and the plasma: tissue ratio is very high (25:1 to 64:1) which suggest that horses treated with this drug at therapeutic doses and slaughtered for meat, that meat products are very unlikely to cause serious adverse effects described below (Lees and Toutain, 2013).

\section{Adverse health effects (cancer and noncancer effects) in humans especially if adverse events.}

There is considerable evidence in the clinical and scientific literature that indicate the most common side-effects of NSAID use, including phenylbutazone, related to inhibition of cyclooxygenase (COX) enzymes in the inflammatory cascade. These effects include: perforation, ulceration and bleeding of the gastrointestinal tract, and uncontrolled hemorrhage leading to internal or external bleeding. Renal damage has also been reported in humans (Cuthbert, 1974; Smolinske et al. 1990).

In 2013, the presence of horse meat in beef burgers and other foods labeled as beef in Europe raised concerns that phenylbutazone which is widely used in horses may be present in horses destined for slaughter and human consumption. Lees and Toutain (2013) recently reviewed the pharmacokinetics and toxicology of phenylbutazone in humans and in horses and have estimated that daily intake for the worst case exposure scenario results in 1/400 of a single therapeutic dose for humans. However, this review and others (Inman, 1977) described this drug at high doses are capable of causing blood dyscrasias, including aplastic anemia, leukopenia, agranulocytosis and thrombocytopenia, and in some cases leading to death in humans. The U.S. national toxicology program, part of the National Institute of Health, has demonstrated some evidence of carcinogenic activity in mice. The mice in these studies showed a chemical-related increased incidence of neoplasms (National Toxicology Program, 2015). However, the World Health Organization's International Agency for Research on Cancer stated that there was inadequate evidence for a carcinogenic effect in humans (IARC, 1987).

\section{Risk management of these specific drug residues.}

Although a thorough risk assessment has not been completed for PBZ due to limited data, there are public health risk (albeit not yet quantifiable) and therefore PBZ is prohibited from use in horses entering the food chain by the United States, the United Kingdom, Canada and the European Union (Dodman et al., 2010; Mariani, 2012). The primary reasons are related to reported adverse health effects described above in adults and children since this drug was approved more than 50 years ago for humans. In 1984, the U.S. FDA began to seriously examine the use of this drug in humans and in 2003, the FDA issued an order prohibiting the extralabel use of animal and human PBZ products in female dairy cattle 20 months of age or older, due to the evidence that residues of these drugs in milk could likely cause an adverse event in humans 
and present a significant public health risk (CFR530.41). The Food Animal Residue Avoidance Databank (FARAD), strongly discourages the use of PBZ in other dairy animals. Any extralabel use of PBZ in animals intended for human consumption in the U.S. carries a greatly extended withhold time (40-50 days after a single dose) due to a zero tolerance policy for residues in the United States (Smith et al. 2008; Mariani et al., 2012). The European Food Safety Authority (EFSA) and the European Medicines Agency (EMA) identified the main risks for the consumer as idiosyncratic blood dyscrasias and the genotoxic/carcinogenic potential for which no maximum residue limits could be established (EFSA, 2013). Phenylbutazone therefore should not be used in animals destined to enter the food supply.

\section{Beta agonists}

\section{Use in Veterinary Medicine}

Adrenergic agonists are sympathomimetic drugs that mimic the action of epinephrine and norepinephrine (Riviere and Papich, 2009). They act on the target cell via membrane-bound Gprotein coupled receptors, and are categorized based on whether they bind to $\alpha$ - or $\beta$ - adrenergic receptors. The adrenergic receptors are further be divided into several subclasses depending on whether they are post-synaptic $\left(\alpha_{1}\right)$ or pre-synaptic $\left(\alpha_{2}\right)$, or the tissue in which they are located $\left(\beta_{1}, \beta_{2}\right)$. Most adrenergic drugs have some activity at both $\alpha$ and $\beta$ receptors, however the ratio of activity varies between drugs and species.

Many tissues contain both subclasses of $\beta$ receptors, however, one subtype usually predominates and provides that particular tissue with its functional classification. An oversimplification relevant to this review can be appreciated by thinking of $\beta_{1}$ receptors as being the most predominant receptor type in the heart and $\beta_{2}$ as being the most predominant receptor subtype present within the pulmonary and vascular smooth muscle. This fact makes the physiological outcome of potential toxicities from consuming meat laden with $\beta$-adrenergic agonists (BAA) residues somewhat obvious, as will be presented later in this review.

In production agriculture systems, BAAs are used as partitioning agents in food animals, whereby they cause a modification of growth by increasing accretion of skeletal muscle and decreasing fat stores (Mersmann, 1998). Use of BAAs late in the feeding period results in consistent increases in the rate of weight gain without an increase in feed consumption, thereby increasing feed efficiency (Loneragan et al., 2014). The mechanism of action of BAAs in repartitioning of fat and muscle have been best explained as agonist action on $\beta_{2}$ receptors that are present in both skeletal muscle and adipocytes (Peters, 1989). The most considerable evidence supports a fat-reducing effect on the size of the adipocytes and an increase in the rate of lipolysis. Additionally, BAA use appears to cause muscle hypertrophy largely by reducing the rate of protein degradation and an increase in nitrogen retention.

Ractopamine hydrochloride was the first BAA approved by the FDA for use in the United States, followed by zilpaterol hydrochloride. One other BAA, clenbuterol hydrochloride, is not approved for use in food animals and its extra-label use is prohibited in the United States (US FDA, 2012). Additionally, clenbuterol has been prohibited from use as a growth promoting agent worldwide (Wu, Deng et al. 2013), however, clenbuterol does have approval in some countries as a tocolytic agent in cows and as an adjunct therapeutic in respiratory disease (Rose, Shearer et al. 1995; Wu, Deng et al. 2013).

\section{Adverse Effects in Humans}


The first report of a drug residue contamination in animal tissue causing human harm was reported in Europe in 1990 (Martinez-Navarro, 1990). Symptoms reported included muscle tremors, cardiac palpitations, nervousness, headache, muscular pain, dizziness, nausea, vomiting, fever, and chills. Two similar outbreaks occurred the following year in Spain where 43 families were affected following consumption of liver tainted with clenbuterol residues (160 - $290 \mathrm{ppb}$ in cooked liver samples). Sporadic outbreaks of clenbuterol toxicity have been and continue to be reported around the world including reports from Spain, Italy, France, Portugal, and China from 1999 - 2011 (Wu et al., 2013).

In toxicology studies, the primary side effects of zilpaterol and ractopamine are those classically related to BAA, such as dose dependent increases in heart rate and decreases in diastolic blood pressure, and they are unlikely to be carcinogenic (U.S. FDA, 1999, U.S. FDA, 2003, U.S. FDA, 2006a, WHO, 2004; 2014). In studies performed in human participants, zilpaterol exhibited a dose dependent increase in heart rate, airway caliber, and systolic blood pressure (WHO, 2014). Ractopamine is approved for use in swine with a withdrawal time (WDT) of 0 days. All formulations of ractopamine are approved for use in cattle with a 0 day WDT, and when approved, zilpaterol had a WDT of 3 days in cattle. It should be noted that there have been no reported cases of adverse health effects in humans exposed to livestock products containing zilpaterol or ractopamine residues.

While clenbuterol displays a very similar toxicity profile in humans, it has physiochemical differences that have attributed to it being not approved for use in food animals in many jurisdictions. There are differences among the BAAs based on the chemical moiety substitution at the aromatic ring which can greatly affect their metabolism, distribution, and longevity within tissue (WHO, 2014; Smith, 1998). Ractopamine and zilpaterol have phenolic and catecholic moieties, respectively, whereas clenbuterol is a substance with an anilinic moiety (Table 2 and Figure 1). Due in part to these chemical differences, residues of clenbuterol are present for longer and in a relatively higher parent compound percentage as compared to ractopamine. Catechols and phenols are rapidly deactivated by metabolism pathways and halogenated BAAs such as clenbuterol are resistant to this rapid deactivation. Clenbuterol undergoes oxidative and conjugative pathways of metabolism and has a longer plasma half-life as compared to ractopamine, which is metabolized by conjugation only, displaying a relatively shorter half-life. Furthermore, clenbuterol has displayed a relatively insensitivity to heat degradation in a range of cooking processes (boiling, roasting, frying, and microwaving) (Rose, Shearer et al. 1995). Clenbuterol was stable under normal cooking conditions, remaining unaltered in cooked edible tissues with little or no leaching into external medium. Only the most extreme cooking conditions resulted in any appreciable loss of clenbuterol from cooked meat (deep frying at $160^{\circ} \mathrm{C}$ for 3 minutes, resulting in inedible charred tissue).

\section{Risk Management}

Zilpaterol was voluntarily pulled from the market by Merck Animal Health in 2013 due to animal welfare concerns and remains off the market at the time of this publication. Codex adopted MRLs for clenbuterol in 2003 and ractopamine in 2012 (CAC, 2012). At the time of this publication, Codex has not formally adopted an MRL for zilpaterol, as can be seen in Table 3; however, JECFA (2015) recently recommended MRLs for zilpaterol for liver (3.5 ppb), kidney (3.3 ppb), and muscle (0.5 ppb) while the U.S. has established a tolerance for liver (12 ppb).

Clenbuterol has a long history of illegal use in the United States, primarily in livestock show animals (Mitchell and Dunnavan, 1998). Anecdotal evidence of its use first came to the 
attention of meat inspection officials in 1988 and methodology development research began to detect it in liver tissue (Mitchell and Dunnavan, 1998). Following these reports, in 1991, the FDA began investigating the domestic use of clenbuterol and shortly thereafter its approval was revoked in the US. The use of clenbuterol as a growth promoting agent is not approved for use in food animals in almost all jurisdictions (Rose, Shearer et al. 1995;Wu, Deng et al. 2013).

\section{Comparison of EU and US Risk Management Guidance}

Despite recent efforts toward harmonization of regulatory systems, there remain significant differences between how risk assessment principles are practiced across the world. Some jurisdictions, such as Japan, monitor chemical residues in food products primarily based on limit of analytical detection rather than attempt to quantitate or classify chemical risks in food to the consumer's public health. The focus of this brief discussion will be on United States (US) and European (EU) approaches extensively reviewed elsewhere (Baynes and Riviere, 2015; Fink-Gremmels, 2012; IOM, 2012). The basis of much of this is rooted in differences between jurisdictions in applying quantitative risk allocation algorithms independent upon the nature of the compound as done by the US; versus the EU's application of the precautionary principle to avoid all risk of harm when specific outcomes are possible (e.g. reproductive endpoints) or as a function of the nature of the product (e.g. hormones, growth promotants) or the technology used to create the product (e.g. recombinant DNA biotechnology, Genetically Modified Organisms (GMO)). These result in complete banning of certain products or significant differences in how a product is used (e.g. therapy versus prevention or growth promotion) or what concentrations are deemed safe for human consumption.

Differences in assumptions relative to dietary intake patterns (e.g. percent of diet consumed as meat or milk) modify these safe and thus allowable food concentrations. Differences exist in how slaughter withdrawal times for exposed food animals are established even after a target tissue concentration, such as a tolerance in the U.S. or a maximum residue level (MRL) in the EU, has been determined. For the same formulation and dosage of a drug, the concept of good veterinary practices may be applied in the EU if judged important to further adjust withdrawal times. Similarly, the U.S. FDA Guidance for Industry \#3 states that the recommended withdrawal periods if followed should provide a high degree of assurance to the producer that the animals treated will be in compliance with applicable regulations, be compatible with livestock management practices, and be reasonable certain to be followed (US FDA, 2006b).

Small differences in how a specific animal is classified may further affect regulatory processes and level of surveillance, as seen when a species such as sheep is variously regulated as a minor species in the U.S. and a major species in part of the EU. In the U.S., state governments do not regulate veterinary drugs since all regulations are promulgated by the US Food and Drug Administration (FDA). In the EU, some drugs are similarly uniformly regulated across the continent while other are restrictively regulated by individual member states.

These philosophical and procedural differences result in different MRLs and tolerances for drugs that are approved for use, and often results in certain drugs being not approved for use in different jurisdictions. Recent incidents where significant regulatory differences exist between 
the US and EU include the use of beta agonists such as ractopamine, hormonal growth promotants such as zeranol, recombinant bovine somatotropin and use of food produced using GMO. Current and future debates surround use of certain antimicrobials compounds and the emerging field of nanotechnology derived medicines.

\section{Acknowledgements}

The authors will like to acknowledge the U.S. Department of Agriculture NIFA for funding the Food Animal Residue Avoidance Database program that has generated the relevant expertise and resources that provided critical guidance in the risk management decisions described in this manuscript. 


\section{References.}

Arifah AK, Lees P. 2002. Pharmacodynamics and pharmacokinetics of phenylbutazone in calves. J Vet Pharmacol Ther. 25(4):299-309.

Baynes, R. E., Martín-Jiménez, T., Craigmill, A. L., and Riviere, J. E. 1999. Estimating provisional acceptable residues for extralabel drug use in livestock. Regul. Toxicol. Pharmacol. 29: 287-299.

Baynes RE, Riviere JE. 2014. Strategies for Reducing Drug and Chemical Residues in Food Animals: International Approaches to Residue Avoidance, Management and Testing. Hoboken: Wiley.

Bendesky, A., Menéndez, D., Ostrosky-Wegman, P. 2002. Is metronidazole carcinogenic?. Mutation Research/Reviews in Mutation Research, 511(2), 133-144.

Bevill, R.F., 1984. Factors influencing the occurrence of drug residues in animal tissues after the use of antimicrobial agents in animal feeds. J. Am. Vet. Med. Assoc. 185, 1124-1126.

Bevill, R.F., 1989. Sulfonamide residues in domestic animals. J. Vet. Pharmacol. Therap. 12, 241-252.

Boothe, D. 2013. Nitroimidazoles. In the Merck Veterinary Manual. New Jersey: Merck Sharp \& Dohme Corp. Retrieved from

http://www.merckmanuals.com/vet/pharmacology/antibacterial_agents/nitroimidazoles.html

Brauer, M. J., Dameshek, W., 1967. Hypoplastic anemia and myeloblastic leukemia following chloramphenicol therapy: report of three cases. N Engl J Med, 277(19), 1003-1005.

Buur, JL., Baynes, R. E., Smith, G., and Riviere, JE. (2006). Use of probabilistic modeling within a physiologic based pharmacokinetic model to predict sulfamethazine residue withdrawal times in edible tissues in swine. Antimicrob. Agent Chemother. 50(7): 2344-2352.

CAC 2011. Joint FAO/WHO Food Standards Programme Codex Committee on Contaminants in Foods, Fifth Session The Hague, The Netherlands, 21 - 25 March 2011.

CAC. 2012. Joint FAO/WHO Food Standard Program Codex Alimentarius Commission Thirtyfifth Session FAO Headquarters, Rome, Italy 2-7 July 2012

CAC. 2013. Joint FAO/WHO Food Standard Program Codex Alimentarius Commission, Residues of Veterinary Drugs in Food. (Codex Classification of Foods and Animal Feeds) 2013. http://www.codexalimentarius.org/. Accessed March 21, 2015.

CAC. 2014. Joint FAO/WHO Food Standard Program Codex Alimentarius Commission Thirtyeighth Session. Maximum Residue Limits (MRLs) and Risk Management Recommendations (RMRs) for Residues of Veterinary Drugs in Foods. Geneva, Switzerland. http://www.codexalimentarius.org/standards/vetdrugs/veterinary-drug-detail/en/?d id=69 
Commission Decision of 11 January. 2005. Laying down harmonized standards for the testing for certain residues in product of animal origin imported from third countries. Official Journal of the European Union L16, 11/01/2005, 61-63.

CONTAM (European Food Safety Authority Panel on Contaminants in the Food Chain). 2014. Scientific Opinion on Chloramphenicol in Food and Feed. EFSA Journal. 12(11),3907.

CFR 530.41. Drugs prohibited for extralabel use in animals. 21CFR530.41. 2003.

CFR 500. Animal Drugs, Feeds, and Related Products; Regulation of Carcinogenic Compounds in FoodProducing Animals. Federal Register / Vol. 77, No. 163 / Wednesday, August 22, 2012 / Rules and Regulations

Cheng Z, McKeller Q, Nolan A. 1998. Pharmacokinetic studies of flunixin meglumine and phenylbutazone in plasma, exudate and transudate in sheep. J Vet Pharmacol Ther.21(4):315-321.

Cheng Z, Welsh E, Nolan A, McKellar QA. 1997. Pharmacokinetic and pharmacodynamic studies on phenylbutazone and oxyphenbutazone in goats. Vet Rec. 11;140(2):40-43.

Choquet-Kastylevsky, G., Vial, T., Descotes, J., 2002. Allergic adverse reactions to sulfonamides. Curr. Allergy Asthma Resp. 2, 16-25.

Cohen, T., Creger, W. P., 1967. Acute myeloid leukemia following seven years of aplastic anemia induced by chloramphenicol. Am J Med. 43(5), 762-770.

Conklin SD, Shockey N, Kubachka K, Howard KD, Carson MC. 2012. Development of an ion chromatography-inductively coupled plasma-mass spectrometry method to determine inorganic arsenic in liver from chickens treated with roxarsone. J Agric Food Chem. 60(37):9394-9404.

Cordle, M.K., 1989. Sulfonamide residues in pork: past, present, and future. J. Anim. Sci. 67, 2810-2816.

Cuthbert, M. F. 1974. "Section 4 Adverse Reactions to Non-steroidal Antirheumatic Drugs." Current Medical Research and Opinion 2.9: 600-610.

Davis, J.L., Smith, G.W., Baynes, R.E., Tell, L.A., Webb, A.I., Riviere, J.E., 2009. Update on drugs prohibited from extralabel use in food animals. J. Am. Vet. Med. Assoc. 235, 528-534.

Dayan AD. (1993). Allergy to antimicrobial residues in food: assessment of the risk to man. Vet Microbiol. 35(3-4): 213-326

de Veau IF, Pedersoli W, Cullison R, Baker J. 2002. Pharmacokinetics of phenylbutazone in beef steers. J Vet Pharmacol Ther. 25(3):195-200.

Dodman, N., Blondeau, N., Marini, AM. 2010. Association of phenylbutazone usage with horses bought for slaughter: A public health risk. Food Chem. Toxicol. 48: 1270-1274. 
Doyle ME. 2006. Veterinary Drug Residues in Processed Meats Potential Health Risk; A Review of the Scientific Literature. Food Research Institute, University of Wisconsin-Madison.

EEC. 1990. Council Regulation (EEC) No. 2377/90. Official Journal of European Communities, L 224/1

EFSA. 2009. SCIENTIFIC OPINION Scientific Opinion on Arsenic in Food1 EFSA Panel on Contaminants in the Food Chain (CONTAM)2, 3 European Food Safety Authority (EFSA), Parma, Italy. EFSA Journal 2009; 7(10):1351

EFSA. 2013. European Medicines Agency. Joint Statement of EFSA and EMA on the presence of residues of phenylbutazone in horse meat. EFSA Journal 11(4):3190

Eliakim-Raz N., Lador A., Leibovici-Weissman Y., Elbaz M., Paul M., Leibovici L., 2015. Efficacy and safety of chloramphenicol: joining the revival of old antibiotics? Systematic review and meta-analysis of randomized controlled trials. J Antimicrob Chemother. 70(4), 979-996.

EMA, 2008. European Medicines Agency. Committee for Veterinary Medicinal Products. Penicillins Summary Report. Canary Wharf, London, UK

EMA, 2009. European Medicines Agency. Status of MRL procedures MRL assessments in the Context of Council Regulations (EEC) No 2377/90. EMEA/CVMP/765/99-Rev.23.

EU. 2010. Commission Regulations (EU) 37/2010. Official Journal of European Union, L 15/1.

\section{EU. 2015. Commission Regulation (EU) 2015/1006 of 25 June 2015 amending Regulation (EC) No 1881/2006 as regards maximum levels of inorganic arsenic in foodstuffs.}

Fink-Gremmels J. 2012. Animal Feed Contamination: Effects on Livestock and Food Safety. Cambridge: Woodhead.

Fraumeni, J. F., 1967. Bone marrow depression induced by chloramphenicol or phenylbutazone: Leukemia and other sequelae. JAMA. 201(11), 828-834.

Fraunfelder, F.W., Fraunfelder, .F.T., 2013. Restricting topical ocular chloramphenicol eye drop use in the United States. Did we overreact? Am J Ophthalmol. 156(3), 420-422.

Gibbons, JF., Boland, F., Buckley, JF., Butler, F., Egan, J., Fanning, S., Markey, BK., Leonard, FC. 2014. Patterns of antimicrobial resistance in pathogenic Escherichia coli isolates from cases of calf enteritis during the spring-calving season. Vet. Microbiol, 170, (1-2), 73-80.

Gomes ER. Demoly P. 2005. Epidemiology of hypersensitivity drug reactions. Curr. Opin. Aller. Clin. Immunol. 5: 309-316. 
Goulden V, Glass D, Cunliffe WJ. 1996. Safety of long-term high-dose minocycline in the treatment of acne. Br J Dermatol. 134: 693-695

Grave, K., Torren-Edo, J., Muller, A., Greko, C., Moulin, G., Mackay D., 2014. Variations in the sales and sales patterns of veterinary antimicrobial agents in 24 European countries. J. Antimicrob. Chemother. 69, 2284-2291.

Grein, K. Duarte, I., 2014. Establishing maximum residue limits in Europe. In: Baynes, RE, Riviere, JE (Eds.), Strategies for Reducing Drug and Chemical Residues in Food Animals: International Approaches to Residue Avoidance, Management and Testing. John Wiley \& Sons, Inc., Hoboken, NJ. USA, pp. 49-63.

IARC, 1987. IARC monographs on the evaluation of the carcinogenic risk of chemicals to man. International Agency for Research on Cancer. p. 316.

Inman, WH. 1977. Study of fatal bone marrow depression with special reference to phenybutazone and oxyphentuazone. Br. Med. J. 1(6075): 1500-1505.

IOM (Institute of Medicine). 2012. Enhancing Safe Foods and Medical Products Through Stronger Regulatory Systems Abroad. Washington: The National Academies Press.

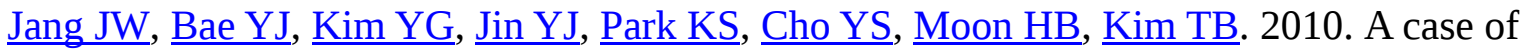
anaphylaxis to oral minocycline. J Korean Med Sci. 25(8):1231-1233.

JECFA. 1994. Joint FAO/WHO Expert Committee on Food Additives (JECFA), 1994. Evaluation of Certain Veterinary Drug Residues in Food. Forty-second Meeting of the Joint FAO/WHO Expert Committee on Food Additives, Chloramphenicol Monograph, FAO Food and Nutrition Paper 41/6, Rome.

JECFA. 2004. Joint FAO/WHO Technical Workshop on Residues of Veterinary Drugs without ADI/MRL. Rome: Joint FAO/WHO Expert Committee on Food Additives, Food and Agriculture Organization of the United Nations (FAO).

JECFA Report 2010. Evaluation of Certain Contaminants in Food. Seventy-second report of the Joint FAO/WHO Expert Committee on Food Additives. Rome, 2010.

JECFA. 2015. Joint FAO/WHO Expert Committee on Food Additives. Summary and Conclusions. Eighty-first meeting (Residues of veterinary drugs), Rome, 17-26 November 2015

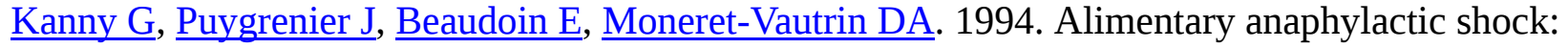
implication of penicillin residues. Allerg Immunol. 26(5):181-183.

Katz SE, Fassbender CA, Dowling JJ Jr. 1973. Oxytetracycline residues in tissue, organs, and eggs of poultry fed supplemented rations. J Assoc Off Anal Chem. 56(1):77-81. 
Lanz, R., Kuhnert, P., Boerlin, P. 2003. Antimicrobial resistance and resistance gene determinants in clinical Escherichia coli from different animal species in Switzerland. Vet Microbiol. 91: 73-84

Laporte, J. R., Vidal, X., Ballarín, E., \& Ibáñez, L., 1998. Possible association between ocular chloramphenicol and aplastic anaemia-the absolute risk is very low. Bri J Clin Pharmacol. 46(2), 181-184.

Lees P., Landoni, M.F., Giraudel, J., Toutain P.L. 2004. Pharmacodynamics and pharmacokinetics of nonsteroidal anti-inflammatory drugs in species of veterinary interest J. Vet Pharmacol. Therap. 27: 479-490

Lees P, Toutain PL. 2013. Pharmacokinetics, pharmacodynamics, metabolism, toxicology and residues of phenylbutazone in humans and horses. Vet J.;196(3):294-303.

Littlefield, N.A., Gaylor, D.W., Blackwell, B.N., Allen, R.R., 1989. Chronic toxicity/carcinogenicity studies of sulphamethazine in B6C3F1 mice. Food Chem. Toxicol. 27, 455-463.

Loneragan, G. H., Thomson, D. U., and Scott, H. M. 2014. Increased mortality in groups of cattle administered the beta-adrenergic agonists ractopamine hydrochloride and zilpaterol hydrochloride. PLoS One, 9, e91177.

Love, D. C., Rodman, S., Neff, R. A., \& Nachman, K. E., 2011. Veterinary drug residues in seafood inspected by the European Union, United States, Canada, and Japan from 2000 to 2009. Environ Sci Technol. 45(17), 7232-7240.

Marini A.M., Blondeau, N., Dodman, N. Food and Chemical Toxicology, 2010, author response to letter by Don Henneke, Sheryl King, William Day and Pat Evans regarding Association of phenylbutazone usage in horses bought for slaughter: A public health risk, Food and Chemical Toxicology 2012; 50:3-4. 455-456.

Martinez-Navarro, J. F. 1990. Food poisoning related to consumption of illicit beta-agonist in liver. Lancet, 336, 1311.

\section{Mason, S., Wu, H., Yeatts, J., and Baynes RE. 2015. Tissue concentrations of sulfamethazine and tetracycline hydrochloride of swine (Sus scrofa domestica) as it relates to withdrawal methods for international export. Reg. Pharmacol. Toxicol. 71(3): 590-596.}

Mersmann, H. J. 1998. Overview of the effects of beta-adrenergic receptor agonists on animal growth including mechanisms of action. J Anim Sci, 76, 160-72.

Mitchell, G. A. and Dunnavan, G. 1998. Illegal use of beta-adrenergic agonists in the United States. J Anim Sci, 76, 208-11. 
Maaland, M.G., Mo, S.S., Schwarz, S., Guardabassi, L., 2015. In vitro assessment of chloramphenicol and florfenicol as second-line antimicrobial agents in dogs. J Vet Pharmacol Ther. 2015 Jan 27. doi: 10.1111/jvp.12204. [Epub ahead of print]

National Toxicology Program. 2015. Phenylbutazone 10354-F. National Institute of Health, 15 Jan. 2015. Web. 28 Jan. 2015.

Papich, M.G., 2012. Selection of antibiotics for meticillin-resistant Staphylococcus pseudintermedius: time to revisit some old drugs? Vet Dermatol, 23(4):352-60.

Papich, M.G., 2013. Antibiotic treatment of resistant infections in small animals. Vet Clin North Am Small Anim Pract. 43(5), 1091-107.

Peters, A. R. 1989. Beta-agonists as repartitioning agents: A review. Vet Rec, 124, 417-420.

Riviere, J. E., Papich, M. G. 2009. Veterinary Pharmacology and Therapeutics, 9th Ed., Wiley-Blackwell.

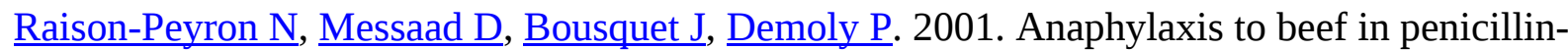
allergic patient. Allergy 56(8): 796-797.

Riviere, J., and Papich, M. 2013. Veterinary Pharmacology and Therapeutics. New Jersey: Wiley-Blackwell.

Settepani, J.A., 1984. The hazard of using chloramphenicol in food animals. J Am Vet Med Assoc. 184(8), 930-931.

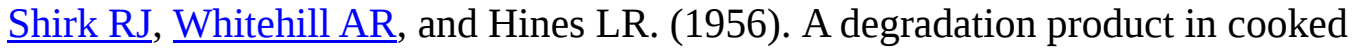
chlortetracycline-treated poultry. 843-848.

Short, J., Zabel, S., Cook, C., Schmeitzel, L., 2014. Adverse events associated with chloramphenicol use in dogs: a retrospective study (2007-2013). Vet Rec. 175(21), 537.

Shu, X., Linet, M., Gao, R., Gao, Y., Brinton, L., Jin, F., Fraumeni, J., 1987. Chloramphenicol use and childhood leukaemia in Shanghai. Lancet. 330(8565), 934-937.

Smick, K.M., Condit, P.K., Proctor, R.L., Sutcher, V., 1964. Fatal aplastic anemia: An epidemiological study of its relationship to the drug chloramphenicol. J Chronic Dis. 17(10), 899-914.

Smith, D. J. 1998. The pharmacokinetics, metabolism, and tissue residues of beta-adrenergic agonists in livestock. J Anim Sci, 76, 173-94.

Smith, GW, Davis, JL., Tell, L., Webb, A., Riviere, JE. Extralabel Use of Nonsteroidal Antiinflammatory Drugs in Cattle. J. Am. Vet. Med. Assoc. 232.5: 697-701. 
Smolinske, SC., Hall, AH, Vandenberg, SA., Spoerke, DG., Mcbride, PV. 1990. Toxic Effects of Nonsteroidal Anti-Inflammatory Drugs in Overdose. Drug Safety. 5.4: 252-274.

Thong BY, Tan TC. 2011. Epidemiology and risk factors for drug allergy. Br J Clin Pharmacol. 71(5): 684-700.

Tran, N., Wilson, N. L., Anders, S., 2012. Standard harmonization as chasing zero (tolerance limits): the impact of veterinary drug residue standards on crustacean imports in the EU, Japan, and North America. Am J Agric Econ. 94(2), 496-502.

U.S. FDA 1999. Freedom of Information Summary: Original new animal drug application (NADA 140-863). Accessed February 10, 2015.

(http://www.fda.gov/downloads/AnimalVeterinary/Products/ApprovedAnimalDrugProducts/FO IADrugSummaries/ucm049990.pdf).

U.S. FDA 2003. Freedom of Information Summary:

Original new animal drug application (NADA 141-221). Accessed February 10, 2015. (http://www.fda.gov/downloads/AnimalVeterinary/Products/ApprovedAnimalDrugProducts/FOI ADrugSummaries/ucm118030.pdf).

U.S .FDA 2006a. Freedom of Information Summary: Original new animal drug application (NADA 141-258). Accessed February 10, 2015.

(http://www.fda.gov/downloads/AnimalVeterinary/Products/ApprovedAnimalDrugProducts/FOI ADrugSummaries/ucm051412.pdf)

U.S. FDA 2006b. Guidance for Industry. General Principles for Evaluating the Safety of Compounds Used in Food-Producing Animals. U.S. Department of Health and Human Services Center for Veterinary Medicine July 25, 2006 Food and Drug Administration. Rockville, MD. USA.

U.S.FDA(2009).http://www.fda.gov/downloads/AnimalVeterinary/SafetyHealth/ProductSafetyIn formation/UCM257547.pdf. Last accessed June 2015

U.S. FDA 2012. Drugs Prohibited for Extralabel Use in Animals. 21 CFR 530.41

U.S. FDA. 2013. New Animal Drugs and New Animal Drug Combination Products Administered in or on Medicated Feed or Drinking Water of Food Producing Animals: Recommendations for Drug Sponsors for Voluntarily Aligning Product Use Conditions with GFI \#209. Center for Veterinary Medicine, Food and Drug Administration, Rockville, MD. USA.

U.S. FDA 2015. Milk Drug Residue Sampling Survey. Center for Veterinary Medicine, Food and Drug Administration, department of health and Human Services, Rockville, MD. USA, March 2015.

U.S FDA. Title 21, Chapter I, Part, 530, Subpart C, Section 530.21. Prohibitions for foodproducing animals. Code of Federal Regulations 2015;6. Available at: 
www.accessdata.fda.gov/scripts/cdrh/cfdocs/cfcfr/CFRSearch.cfm?fr=530.21. Accessed Sept 10, 2015.

USDA 2012. New Analytic Methods and Sampling Procedures for the United States National Residue Program for Meat, Poultry, and Egg Products. 77 Fed. Reg. 130 (6 July 2012), 3989539899.

Venable, R., Haynes, C., Cook, J. M., 2014. Reported prevalence and quantitative LC-MS methods for the analysis of veterinary drug residues in honey: a review. Food Addit Contam Part A. 31(4), 621-640.

Wallerstein, R.O., Condit, P.K., Kasper, C.K., Brown, J.W., Morrison, F.R., 1969. Statewide study of chloramphenicol therapy and fatal aplastic anemia. J. Am. Med. Assoc. 208, 2045-2050.

Wongtavatchai, J., McLean, L. G., Ramos, F., Arnold, D., 2004. WHO Food Additives series 53: Chloramphenicol. JECFA (WHO: Joint FAO/WHO Expert Committee on Food Additives), IPCS (International Programme on Chemical Safety) INCHEM. 7-85.

WHO. 2004. World Health Organization. WHO Food Additive Series: 53; Ractompaine. http://www.inchem.org/documents/jecfa/jecmono/v53je08.htm\#abs.

WHO. 2014. WORLD HEALTH, Organization. 2014. Evaluation of certain veterinary drug residues in food. Seventy-eighth report of the Joint FAO/WHO Expert Committee on Food Additives. World Health Organ Tech Rep Ser, 1-123, back cover.

Wu,, M. L., Deng, J. F., Chen, Y., Chu, W. L., Hung, D. Z. \& Yang, C. C. 2013. Late diagnosis of an outbreak of leanness-enhancing agent-related food poisoning. Am J Emerg Med, 31, 1501-3. 
Table 1. U.S. tolerances, EU MRLs and US withdrawal times for selected drugs.

\begin{tabular}{|c|c|c|c|c|}
\hline $\begin{array}{l}\text { U.S. Approved } \\
\text { Drugs }\end{array}$ & ${ }^{1}$ U.S. Tolerance & ${ }^{2}$ EU MRL & $\begin{array}{c}{ }^{1} \text { U.S. Milk } \\
\text { Withdrawal } \\
\text { Time }\end{array}$ & $\begin{array}{c}{ }^{1} \text { U.S. Meat } \\
\text { Withdrawal } \\
\text { Time }\end{array}$ \\
\hline \multicolumn{5}{|l|}{ Penicillins } \\
\hline $\begin{array}{l}\text { Benzylpenicillin } \\
\text { (PEN-G-MAX®) }\end{array}$ & $\begin{array}{c}\text { 0 ppb (milk) } \\
5 \text { ppb (milk safe level }{ }^{3} \text { ) } \\
50 \text { ppb (meat) }\end{array}$ & $\begin{array}{c}4 \text { ppb (milk) } \\
50 \text { ppb (edible } \\
\text { tissue) }\end{array}$ & $\begin{array}{c}48 \text { Hours } \\
\text { (cattle) }\end{array}$ & $\begin{array}{l}10 \text { days } \\
\text { (cattle) }\end{array}$ \\
\hline \multicolumn{5}{|l|}{ Tetracyclines } \\
\hline $\begin{array}{l}\text { Oxytetracycline } \\
\left.\qquad \text { (Liquamycin }{ }^{\circledR}\right)\end{array}$ & $\begin{array}{c}300 \text { ppb (milk) } \\
\text { 12,000 ppb (kidney) } \\
\text { 6,000 ppb (liver) } \\
\text { 2,000 ppb (meat) }\end{array}$ & $\begin{array}{c}100 \text { ppb (milk) } \\
600 \text { ppb (kidney) } \\
300 \text { ppb (liver) } \\
100 \text { ppb (muscle) }\end{array}$ & $\begin{array}{l}96 \text { Hours } \\
\text { (cattle) }\end{array}$ & $\begin{array}{l}28 \text { days } \\
\text { (cattle) }\end{array}$ \\
\hline \multicolumn{5}{|l|}{ Aminoglycosides } \\
\hline $\begin{array}{r}\text { Gentamicin } \\
\text { (Garacin }{ }^{\circledR} \text { Piglet } \\
\text { Injection) } \\
\text { (Gentocin }{ }^{\circledR} \text { Pink Eye } \\
\text { Spray) }\end{array}$ & $\begin{array}{c}30 \text { ppb (milk safe level) } \\
400 \text { ppb (kidney) } \\
300 \text { ppb (liver) } \\
400 \text { ppb (fat) } \\
100 \text { ppb (meat) }\end{array}$ & $\begin{array}{c}100 \text { ppb (milk) } \\
750 \text { ppb (kidney) } \\
200 \text { ppb (liver) } \\
50 \text { ppb (fat) } \\
50 \text { ppb (muscle) }\end{array}$ & $\begin{array}{c}\text { NA } \\
\text { 0 days } \\
\text { (cattle) }\end{array}$ & $\begin{array}{l}40 \text { days } \\
\text { (pigs) } \\
0 \text { days } \\
\text { (cattle) }\end{array}$ \\
\hline \multicolumn{5}{|l|}{ Sulfonamides } \\
\hline $\begin{array}{l}\text { Sulfamethazine } \\
\left.\qquad \text { (Sulmet }{ }^{\circledR}\right)\end{array}$ & 100 ppb (Edible Tissues)) & 100 ppb (all tissues) & NA & $\begin{array}{c}15 \text { days } \\
\text { (pigs) }\end{array}$ \\
\hline
\end{tabular}

${ }^{1}$ Obtained from Food Animal Residue Avoidance Databank; www.FARAD.org.

${ }^{2}$ Obtained from European Medicine Agency://www.ema.europa.eu/ema/

${ }^{3}$ Safe levels are not and cannot be transformed into tolerances that are established for animal drugs and do not have the force of law of tolerances, or of binding rules 
Table 2 - Chemical subcategory for each $\beta$-adrenergic agonist as defined by its aromatic substitution group. Substitution group determines the biotransformation pathway and ultimately the pharmacokinetic properties of each drug.

\begin{tabular}{|l|l|l|l|}
\hline \multicolumn{1}{|c|}{ Category } & \multicolumn{1}{c|}{ Drug } & \multicolumn{1}{c|}{$\begin{array}{c}\text { Aromatic } \\
\text { Substitution }\end{array}$} & \multicolumn{1}{|c|}{ Biotransformation Pathway } \\
\hline Phenol & Ractopamine & $4-\mathrm{OH}$ & Conjugation \\
\hline Haloaniline & Clenbuterol & $3-, 5-\mathrm{Cl} ; 4-\mathrm{NH}_{2}$ & Conjugation and Oxidation \\
\hline Catechol & Zilpaterol & $4-, 5-\mathrm{OH}$ & $\begin{array}{l}\text { Catechola m ine O-m e th yI } \\
\text { transferases }\end{array}$ \\
\hline
\end{tabular}

Table 3 - Maximum residue limits (MRLs) for $\beta$-adrenergic agonists associated with food animal production as approved by Codex Alimentarius. All values are parts per billion (ppb).

\begin{tabular}{|l|c|c|c|c|c|}
\hline \multicolumn{1}{|c|}{ Drug } & $\begin{array}{c}\text { Muscl } \\
\mathrm{e}\end{array}$ & $\begin{array}{c}\text { Kidne } \\
\mathrm{y}\end{array}$ & Fat & $\begin{array}{c}\text { Liv } \\
\text { er }\end{array}$ & Comment \\
\hline Ractopamine & 10 & 90 & 10 & 40 & - \\
\hline Clenbuterol & 0.2 & 0.6 & 0.2 & 0.6 & $\begin{array}{l}\text { MRLs are applicable only when } \\
\text { associated with a nationally approved } \\
\text { therapeutic use. }\end{array}$ \\
\hline Zilpaterol & 0 & 0 & 0 & 0 & - \\
\hline
\end{tabular}


Figure

Figure 1<smiles>CC(C)(C)NCC(O)c1cc(Cl)c(N)c(Cl)c1</smiles><smiles>[R]OC(=O)O[Na]</smiles>

Figure - Chemical structures of three $\beta$-adrenergic agonists. 